Artikel Penelitian

\title{
Hubungan Antara Anemia pada Ibu Hamil dan Kejadian Persalinan Preterm di RSUP M. Djamil Padang Tahun 2013
}

\author{
Aulia Ulfa ${ }^{1}$, Ariadi $^{2}$, Elmatris $^{3}$
}

\begin{abstract}
Abstrak
Anemia merupakan salah satu masalah kesehatan yang paling sering dialami selama kehamilan. Anemia ibu hamil diketahui sebagai salah satu faktor risiko persalinan preterm. Penelitian sebelumnya tahun 2012 di RSUP Dr. M. Djamil Padang mendapatkan dari seluruh pasien persalinan preterm sebagian besar (76,39\%) memiliki riwayat anemia dalam kehamilan. Tujuan penelitian ini adalah menentukan antara hubungan anemia pada ibu hamil dan kejadian persalinan preterm di RSUP Dr. M. Djamil Padang tahun 2013. Jenis penelitian ini adalah analitik observasional dengan desain cross sectional. Berdasarkan kriteria sampel yang telah ditentukan, didapatkan sampel 30 ibu persalinan preterm sebagai kelompok kasus dan 30 ibu persalinan aterm yang diambil secara simple random sampling sebagai kelompok kontrol. Data dianalisis dengan Chi-square test dan Independent $t$-test $(\alpha=0.05)$. Hasil penelitian menunjukan bahwa ibu yang melakukan persalinan di RSUP Dr. M. Djamil Padang tahun 2013, terbanyak berusia $20-$ 35 tahun $(71,7 \%)$ dan multipara (55,0\%). Ibu yang melakukan persalinan $40 \%$ mengalami anemia. Hasil uji statistik Chi-square menunjukan terdapat hubungan anemia pada ibu hamil dengan kejadian persalinan preterm (nilai $p=$ 0,018, OR= 4,297). Rata-rata kadar $\mathrm{Hb}$ pada kelompok persalinan preterm $(10,62 \pm 1,42) \mathrm{g} / \mathrm{dl}$ lebih rendah dibandingkan kelompok persalinan aterm $(11,51 \pm 1,06) \mathrm{g} / \mathrm{dl}$ dan bermakna secara statistik $(p=0,007)$. Simpulan penelitian ini adalah terdapat hubungan bermakna antara kejadian anemia dan persalinan preterm.
\end{abstract}

Kata kunci: anemia ibu hamil, persalinan preterm, $\mathrm{Hb}$

\section{Abstract}

Anemia is one of the most often health problem during pregnancy. Anemia during pregnancy is known as one of preterm delivery risk factors. Previous study in 2012, RSUP M. Djamil padang shows that most of preterem delivery patients $(76,39 \%)$ had anemia history during pregnancy. The objective of this study was to determine between maternal anemia during pregnancy and preterm delivery. This was an observational analytic study by using cross sectional design. Based on determined sample criteria, there were 30 preterm delivery's patients as case group and 30 aterm delivery's patients selected by using simple random sampling as control group. The data analysis was done using Chi-square test and Independent $t$-test $(\alpha=0.05)$. The result of study shows that most of women who deliver in RSUP M. Djamil Padang in 2013, had age 20-35 years old (71,7\%) and multipara (55,0\%). There was 40\% women with maternal anemia during pregnancy. The statistic test using Chi-square shows that there was relation of maternal anemia during pregnancy with preterm delivery ( $p$ value $=0,018, O R=4,297$ ). The average of $\mathrm{Hb}$ concentration preterm delivery group $(10,62 \pm 1,42) \mathrm{g} / \mathrm{dl}$ was lower than aterm delivery group $(11,51 \pm 1,06) \mathrm{g} / \mathrm{dl}$ and statistically significant ( $p$ value $=0,007$ ). It can be concluded that there is association between anemia incident and preterm delivery.

Keywords: preterm delivery, anemia during pregnancy, $\mathrm{Hb}$

Affiliasi penulis: 1. Prodi Profesi Dokter FK Unand (Fakultas Kedokteran Universitas Andalas Padang), 2. Bagian Obstetri dan Ginekologi FK Unand/RSUP Dr. M. Djamil Padang, 3. Bagian Kimia FK Unand
Korespondensi: Aulia Ulfa, Email : au.auliaulfa@gmaill.com, Telp: 08192755662 


\section{PENDAHULUAN}

Indonesia sebagai salah satu negara yang menjalankan program Milenium Development Goals, memiliki target menurunkan Angka Kematian Ibu (AKI) mmenjadi 102 per 100.000 kelahiran hidup dan Angka Kematian Bayi (AKB) menjadi 20 per 1000 kelahiran hidup pada tahun 2015. ${ }^{1}$ Menurut data WHO (World Health Organization) tiga tahun terakhir, AKB di Indonesia masih belum mencapai target. Kematian bayi terbanyak (48\%) terjadi pada bulan pertama atau masa neonatus, dan penyebab terbanyak (44\%) kematian neonatus adalah prematuritas. ${ }^{2}$

Prematuritas atau persalinan preterm adalah persalinan yang terjadi pada kehamilan 20 sampai 36 minggu. ${ }^{3}$ Menurut analisis data WHO tahun 2012, angka kejadian prematuritas di Indonesia mencapai $15,5 \%$ dan menduduki 10 besarangka kejadian prematuritas tertinggi di dunia. ${ }^{2}$ Survei awal yang dilakukan didapatkan jumlah persalinan preterm yang tercatat di Instalasai Rekam Medik RSUP dr. M. Djamil Padang tahun 2012 sebanyak 90 (5,4\%) dari seluruh persalinan dan meningkat pada tahun 2013 sebanyak $194(11,3 \%)$ dari seluruh persalinan.

Anemia ibu hamil merupakan salah satu faktor risiko persalinan preterm. ${ }^{4}$ Menurut Centers for Disease Control and Prevention (CDC), anemia dalam kehamilan adalah kondisi ibu dengan kadar hemoglobin di bawah $\leq 11 \mathrm{~g} / \mathrm{dl}$ pada trimester satu dan tiga, atau $\leq 10,5 \mathrm{~g} / \mathrm{dl}$ pada trimester dua. ${ }^{5} \mathrm{WHO}$ melaporkan bahwa $34 \%$ ibu hamil di dunia menderita anemia pada kehamilannya, dan $75 \%$ diantaranya berada di Negara sedang berkembang. ${ }^{6}$ Menurut data Riskesdas tahun 2013 terdapat peningkatan prevalensi anemia pada ibu hamil menjadi $37,1 \%{ }^{7}$ Prevalensi anemia pada ibu hamil di Sumatera Barat $15,92 \%$ pada tahun 2012 dan meningkat menjadi $18,43 \%$ pada tahun $2013 .^{8}$

Secara biologis, mekanisme persalinan preterm disebabkan oleh hipoksia, stres oksidatif, dan infeksi maternal. Hipoksia kronis yang disebabkan oleh anemia atau kadar hemoglobin rendah dapat menginduksi stres ibu dan janin. Respon terhadap stress akan memicu pelepasan $\mathrm{CRH}$ (Corticotropin Releasing Hormon) dan peningkatan produksi kortisol yang selanjutnya akan menginduksi persalinan preterm. ${ }^{9}$ Stres oksidatif yang disebabkan anemia defisiensi besi akan mengakibatkan kerusakan eritrosit, sehingga sirkulasi utero-plasenta akan terganggu dan unit fetal maternal rusak. Keadaan tersebut akan memicu terjadinya persalinan preterm. Risiko infeksi maternal meningkat pada anemia defisiensi besi. Infeksi maternal akan memicu peningkatan produksi sitokin inflamasi, prostaglandin, dan $\mathrm{CRH}$ yang menginduksi terjadinya persalinan preterm. $^{10}$

Hasil penelitian sebelumnya di RSUP Muhammad Hoesin Palembang tahun 2000-2002, melaporkan bahwa anemia pada ibu hamil $(\mathrm{Hb}<10,6$ gr\%) berhubungan signifikan dengan persalinan preterm dan ibu hamil dengan kadar hemoglobin $<10,5$ gr\% berisiko 2,5 kali mengalami persalinan preterm dibandingkan dengan ibu yang mempunyai kadar hemoglobin normal $(\mathrm{Hb}>10,6 \mathrm{gr} \%) .{ }^{11}$ Berdasarkan penelitian Edrin et al (2013) di RSUP Dr. M. Djamil Padang tahun 2012, dari keseluruhan pasien persalinan preterm, sebagian besar $(76,39 \%)$ pasien memiliki riwayat anemia dengan rata-rata kadar hemoglobin ibu hamil adalah $9,4 \mathrm{gr} \%{ }^{12}$

\section{METODE}

Penelitian ini merupakan penelitian analitik observasional yang didasarkan dari data rekam medik di Instalasi Rekam Medik RSUP Dr. M. Djamil Padang. Rancangan penelitian yang digunakan adalah cross sectional. Populasi pada penelitian ini adalah semua data rekam medis ibu yang melakukan persalinan di RSUP Dr. M. Djamil Padang periode 1 Januari - 31 Desember 2013. Sampel penelitian adalah bagian populasi yang memenuhi criteria inklusi dan eksklusi. Kriteria inklusi adalah lbu hamil yang melakukan persalinan di RSUP Dr. M. Djamil Padang periode 1 Januari - 31 Desember 2013 dengan data rekam medik yang lengkap terhadap variabel yang ingin diteliti, dan kelahiran tunggal. Kriteria ekslusi adalah ibu hamil yang mengalami perdarahan antepartum, ketuban pecah dini, preeklampsia/eklmapsia, dan infeksi. Analisis data dilakukan dengan menggunakan analisis univariat, yaitu analisis yang menggambarkan distribusi dan persentase dari setiap variabel dan analisis bivariat untuk mengetahui besar pengaruh hubungan antara variable terikat dan variable bebas. 
Analisis hubungan anemia pada ibu hamil dengan kejadian persalinan preterm, menggunakan uji Chi-square $(\alpha=0.05)$. Analisis perbedaan kadar $\mathrm{Hb}$ ibu hamil pada persalinan preterm dan aterm menggunakan uji independent $t$-test $(\alpha=0.05)$.

\section{HASIL}

Penelitian yang telah dilakukan pada $30 \mathrm{ibu}$ persalinan preterm dan 30 ibu yang mengalami persalinan aterm di RSUP Dr. M. Djamil Padang periode 1 Januari 2013 - 31 Desember 2013, didapatkan data penelitian yang ditabulasikan sebagai berikut.

Tabel 1. Karakteristik ibu yang melakukan persalinan di RSUP Dr. M. Djamil Padang berdasarkan usia dan paritas tahun 2013.

\begin{tabular}{ccc}
\hline Karakteristik & $\mathbf{f}$ & $\%$ \\
\hline Usia ibu & 2 & 3,3 \\
$<20$ tahun & 43 & 71,7 \\
$20-35$ tahun & 15 & 25,0 \\
$>35$ tahun & 60 & 100 \\
Jumlah & & \\
Paritas & & \\
Primipara (1) & 20 & 33,3 \\
Multipara (2 - 4) & 33 & 55,0 \\
Grandemultipara ( $\geq 5)$ & 7 & 11,7 \\
Jumlah & 60 & 100 \\
\hline
\end{tabular}

Tabel 2. Distribusi frekuensi anemia pada ibu hamil di RSUP Dr. M. Djamil Padang tahun 2013

\begin{tabular}{ccc}
\hline Kelompok & $\mathbf{f}$ & $\%$ \\
\hline Anemia $(\mathrm{Hb}<11 \mathrm{~g} / \mathrm{dl})$ & 24 & 40,0 \\
Tidak anemia $(\mathrm{Hb} \geq 11 \mathrm{~g} / \mathrm{dl})$ & 36 & 60,0 \\
Jumlah & 76 & 100 \\
\hline
\end{tabular}

Tabel 3. Hubungan anemia pada ibu hamil dengan kejadian persalinan preterm di RSUP Dr. M. Djamil Padang tahun 2013

\begin{tabular}{|c|c|c|c|c|c|c|}
\hline \multirow{3}{*}{$\begin{array}{c}\text { Anemia } \\
\text { ibu } \\
\text { hamil }\end{array}$} & \multicolumn{4}{|c|}{ Persalinan } & \multirow{3}{*}{ p } & \multirow{3}{*}{$\begin{array}{l}\text { Odd } \\
\text { Ratio }\end{array}$} \\
\hline & \multicolumn{2}{|c|}{ Preterm } & \multicolumn{2}{|c|}{ Aterm } & & \\
\hline & f & $\%$ & $f$ & $\%$ & & \\
\hline Anemia & 17 & 70,8 & 7 & 29,2 & & \\
\hline $\begin{array}{c}\text { Tidak } \\
\text { anemia }\end{array}$ & 13 & 36,1 & 23 & 63,9 & 0,018 & 4,297 \\
\hline Jumlah & 30 & 50 & 30 & 50 & & \\
\hline
\end{tabular}

Tabel 4. Perbedaan kadar $\mathrm{Hb}$ pada persalinan preterm dan aterm

\begin{tabular}{cccc}
\hline Persalinan & $\mathbf{n}$ & $\begin{array}{c}\text { Kadar Hb (g/d) } \\
\text { (Rerata } \pm \text { SD) }\end{array}$ & $\mathbf{p}$ \\
\hline Preterm & 30 & $10,62 \pm 1,42$ & 0,007 \\
Aterm & 30 & $11,51 \pm 1,06$ & \\
\hline
\end{tabular}

\section{PEMBAHASAN}

Hasil penelitian pada Tabel 1 menunjukan bahwa ibu yang melakukan persalinan di RSUP Dr. M. Djamil Padang periode tahun 2013 terbanyak berusia diantara 20-35 tahun yaitu 43 ibu(71,7\%). Penelitian sebelumnya di RSUD Ambarawa periode Maret Oktober 2013 juga menunjukan bahwa ibu yang melakukan persalinan terbanyak berusia diantara 2035 tahun yaitu 127 ibu $(80,0 \%) .^{13}$

Ibu yang melakukan persalinan di RSUP Dr. M. Djamil Padang tahun 2013, terbanyak adalah ibu dengan multipara yaitu 33 ibu (55,0\%). Hasil penelitian ini berbeda dengan penelitian di RSUD Moewardi Surakarta yang menunjukan bahwa lebih banyak ibu dengan primipara yaitu 99 ibu $(66,0 \%)$ yang melakukan persalinan periode Mei - Juni 2013. ${ }^{14}$ Perbedaan status paritas dapat terjadi dikarenakan oleh lokasi dan waktu penelitian yang berbeda. Baik ibu dengan primipara maupun multipara memiliki peluang yang sama untuk mengalami persalinan.

Pada Tabel 2 terlihat ibu hamil tidak anemia yaitu $36 \mathrm{ibu}(60,0 \%)$ yang melakukan persalinan di RSUP Dr. M. Djamil Padang tahun 2013 dibandingkan ibu hamil anemia yaitu 24 ibu (40\%). Penelitian dengan desain penelitian yang sama juga menunjukan bahwa lebih banyak ibu hamil tidak anemia yaitu 172 ibu $(91,5 \%)$ dibandingkan ibu hamil anemia yaitu 16 ibu $(8,5 \%)$ yang melakukan persalinan di RSIA Siti Fatimah Makassar periode 2011-2012. ${ }^{15}$ Penelitian sebelumnya di RSUD Ambarawa juga menunjukan bahwa lebih banyak ibu hamil tidak anemia yaitu 117 ibu $(73,6 \%)$ dibandingkan ibu hamil anemia yaitu 42 ibu (26,4\%). Penelitian di RSUD Ambarawa menjelaskan bahwa rendahnya kejadian anemia ibu hamil di RSUD ini dikarenakan ibu hamil memiliki kesadaran yang cukup tinggi untuk mengonsumsi tablet tambah darah dan menjaga pola makan sehat selama kehamilan. ${ }^{13}$ 
Hasil penelitian pada Tabel 3 menunjukan bahwa pada kelompok persalinan preterm lebih banyak ibu hamil anemia (70,8\%) dibandingkan ibu hamil tidak anemia (29,2\%). Pada kelompok persalinan aterm lebih banyak ibu hamil tidak anemia $(63,9 \%)$ dibandingkan ibu hamil anemia (36,1\%). Berdasarkan hasil uji statistik Chi-square didapatkan nilai $p=0,018$, sehingga dapat disimpulkan bahwa terdapat hubungan bermakna antara anemia pada ibu hamil dengan kejadian persalinan preterm $(p<0,05)$. Hasil penelitian yang sama juga didapatkan di RSUD Dr. Moewardi Surakarta yang menunjukan bahwa ada hubungan yang signifikan antara anemia pada ibu hamil terhadap persalinan preterm dengan nilai $p=$ $0,001(p<0,05) .^{16}$

Mekanisme persalinan preterm disebabkan oleh hipoksia, stres oksidatif, dan infeksi maternal. Anemia atau kadar hemoglobin rendah menyebabkan jaringan plasenta kekurangan suplai oksigen sehingga dapat terjadi hipoksia kronis yang menginduksi stres ibu dan janin. Respon terhadap stress akan memicu pelepasan $\mathrm{CRH}$ (Corticotropin Releasing Hormon) dan peningkatan produksi kortisol yang selanjutnya akan menginduksi persalinan preterm. ${ }^{9}$ Stres oksidatif yang disebabkan anemia defisiensi besi akan mengakibatkan kerusakan eritrosit, sehingga sirkulasi utero-plasenta akan terganggu dan unit fetal maternal rusak. Keadaan tersebut akan memicu terjadinya persalinan preterm. Risiko infeksi maternal meningkat pada anemia defisiensi besi. Infeksi maternal akan memicu peningkatan produksi sitokin inflamasi, prostaglandin, dan $\mathrm{CRH}$ yang menginduksi terjadinya persalinan preterm. ${ }^{10}$

Berdasarkan hasil uji statistik untuk melihat risiko anemia ibu hamil pada persalinan preterm didapatkan odd ratio $=4,297$, sehingga dapat disimpulkan bahwa ibu hamil anemia memiliki risiko 4,297 kali untuk mengalami persalinan preterm dibandingkan ibu hamil tidak anemia, dan anemia pada ibu hamil merupakan faktor risiko terjadinya persalinan preterm $(O R>1)$. Penelitian sebelumnya di Rumah Sakit Ibu dan Anak Budi Kemulian Jakarta juga menunjukan bahwa ibu hamil yang menderita anemia berisiko 4,38 kali untuk mengalami persalinan preterm dibandingkan ibu hamil tidak anemia. ${ }^{17}$
Berdasarkan hasil penelitian pada Tabel 4 didapatkan rerata kadar $\mathrm{Hb}$ pada kelompok persalinan preterm $(10,62 \pm 1,42) \mathrm{g} / \mathrm{dl}$ lebih rendah dibandingkan kelompok persalinan aterm $(11,51 \pm 1,06) \mathrm{g} / \mathrm{dl}$. Hasil uji statistik menggunakan uji $T$-test didapatkan nilai $p=$ $0,007$ ( $p<0,05)$, sehingga secara statistik dapat disimpulkan bahwa terdapat perbedaan bermakna kadar $\mathrm{Hb}$ antara kelompok persalinan preterm dan aterm. Penelitian sebelumnya di RSUP Dr. M. Djamil Padang tahun 2012 mendapatkan rerata kadar $\mathrm{Hb}$ ibu hamil pada persalinan preterm yang lebih rendah yaitu 9,4 g/dl dengan kadar $\mathrm{Hb}$ minimum $7,2 \mathrm{~g} / \mathrm{dl}$ dan maksimum $12 \mathrm{~g} / \mathrm{dl}$.

\section{SIMPULAN}

Terdapat hubungan yang bermakna antara anemia pada ibu hamil dengan kejadian persalinan preterm di RSUP Dr. M. Djamil Padang tahun 2013, dan ibu hamil anemia memiliki risiko 4,297 kali untuk mengalami persalinan preterm dibandingkan ibu hamil tidak anemia. Terdapat perbedaan bermakna kadar $\mathrm{Hb}$ antara kelompok persalinan preterm dan aterm.

\section{UCAPAN TERIMA KASIH}

Terima kasih kepada Kepala dan segenap staff Instalasi Rekam Medik RSUP M. Djamil Padang yang telah membantu terlaksananya penelitian ini.

\section{DAFTAR PUSTAKA}

1. United Nation Population Fund. Achieving the millenium development goals. Population and Development Strategies Number 10. 2003.

2. World Health Organization (WHO). Levels and trends in child mortality report 2013. World Health Statistic 2013. 2014.

3. Slattery MM, Morrison JJ. Preterm delivery. The Lancet. 2008; 360.

4. Cunningham GF, Gant NF, Leveno KJ, Gilstrap LC, Hauth JC, Wenstrom KD. Williams Obstetrics. Hartono Andry. Jakarta: EGC; 2013.

5. Centers for Disease Control and Prevention (CDC). Anemia in pregnancy. 2012 (diunduh 1 Februari 2015). Tersedia dari: URL: HYPERLINK http://www.cdc.gov/nchs/ 
6. World Health Organization (WHO). Make every mother and child count. The World Health Report. 2005.

7. Departemen Kesehatan Republik Indonesia. Riset kesehatan dasar tahun 2013. 2013; 12-3.

8. Dinas Kesehatan Sumatera Barat. Laporan dinas kesehatan Sumatera Barat. 2014.

9. Hacker NF, Gambone JC, Hobel CJ. Hacker and moore's essentials of obstetrics and gynecology. Edisi ke-5. New York: Elsevier; 2010.

10. Parker JA, Filipa B, Simon JS, Helen S, Sally H, Carolyn JD, et al. Gaps in The evidence for prevention and teatment of maternal anemia: review of systematic review. BMC Pregnancy and Childbirth. 2012;12(56). (diunduh 5 Februari 2015). Tersedia dari: URL: HYPERLINK http://www. biomedcentral.com/14712393/12/5

11. Asmawawarman. Hubungan anemia ibu hamil dengan persalinan preterm di Rumah Sakit Umum Pusat Mohammad Hoesin Palembang (tesis). Jakarta: Fakultas Kedokteran Universitas Indonesia. 2002.

12. Edrin VL, Ariadi, Irawati L. Gambaran karakteristik ibu hamil pada persalinan preterm di RSUP Dr. M. Djamil Padang tahun 2012. Jurnal Kesehatan Andalas. 2014;3(3): 311-7.
13. Amartha TAS, Mulyasari I, Widyawati SA. Hubungan anemia pada ibu hamil dengan kejadian persalinan prematur di RSUD Ambarawa. Jurnal DIV Kebidanan STIKES Ngudi Waluyo Ungaran. 2014:84-90.

14. Trisnawati AM. Hubungan antara multparitas dengan kejadian partus preterm. karya tulis IImiah. Fakultas Kedokteran Universitas Sebelas Maret; 2013.

15. Paembonan N, Ansar J, Arsyad DS. Faktor risiko kejadian kelahiran prematur di rumah sakit ibu dan anak Siti Fatimah Kota Makassar. Makassar: Fakutas Kesehatan Masyarakat Universitas Hasanuddin; 2014.

16. Sulastri, Rahmawati D. Analisis kadar hemoglobin ibu hamil terhadap kejadian persalinan preterm di RSUD Dr. Moewardi Surakarta. Prosiding Konferensi Nasional PPNI Jawa Tengah. 2013;150-3.

17. Irmawati. Pengaruh Anemia ibu hamil dengan terjadinya persalinan prematur di Rumah Sakit Ibu dan Anak Budi Kemulian Jakarta (tesis). Jakarta: Fakultas Kesehatan Masyarakat Universitas Indonesia; 2010. 